\title{
Combined over-the-scope clip and detachable snare placement for closure of an enterocutaneous fistula
}

A 75-year-old man underwent a laparoscopic extended right hemicolectomy for malignant colorectal adenocarcinoma of the distal transverse colon. The postoperative course was complicated by pneumonia in the left lung and acute pancreatitis. The patient presented 30 days after surgery with increased abdominal pain and septic shock.

Abdominal computed tomography revealed a $111 \times 81 \times 195 \mathrm{~mm}$ intra-abdominal collection in the left paracolic gutter, which was percutaneously drained, with clinical improvement. Then, 1 week later, an enterocutaneous fistula (ECF) was identified after contrast instillation through the percutaneous drain. Given the lack of improvement with nonoperative management, endoscopic closure was attempted 68 days after the original surgery ( $>$ Video 1 ).

A therapeutic endoscope was advanced to the ileocolic anastomosis, located at the splenic flexure. Endoscopic and fluoroscopic views did not initially reveal the location of the fistula. Instillation of methylene blue through the percutaneous drain revealed the fistula location
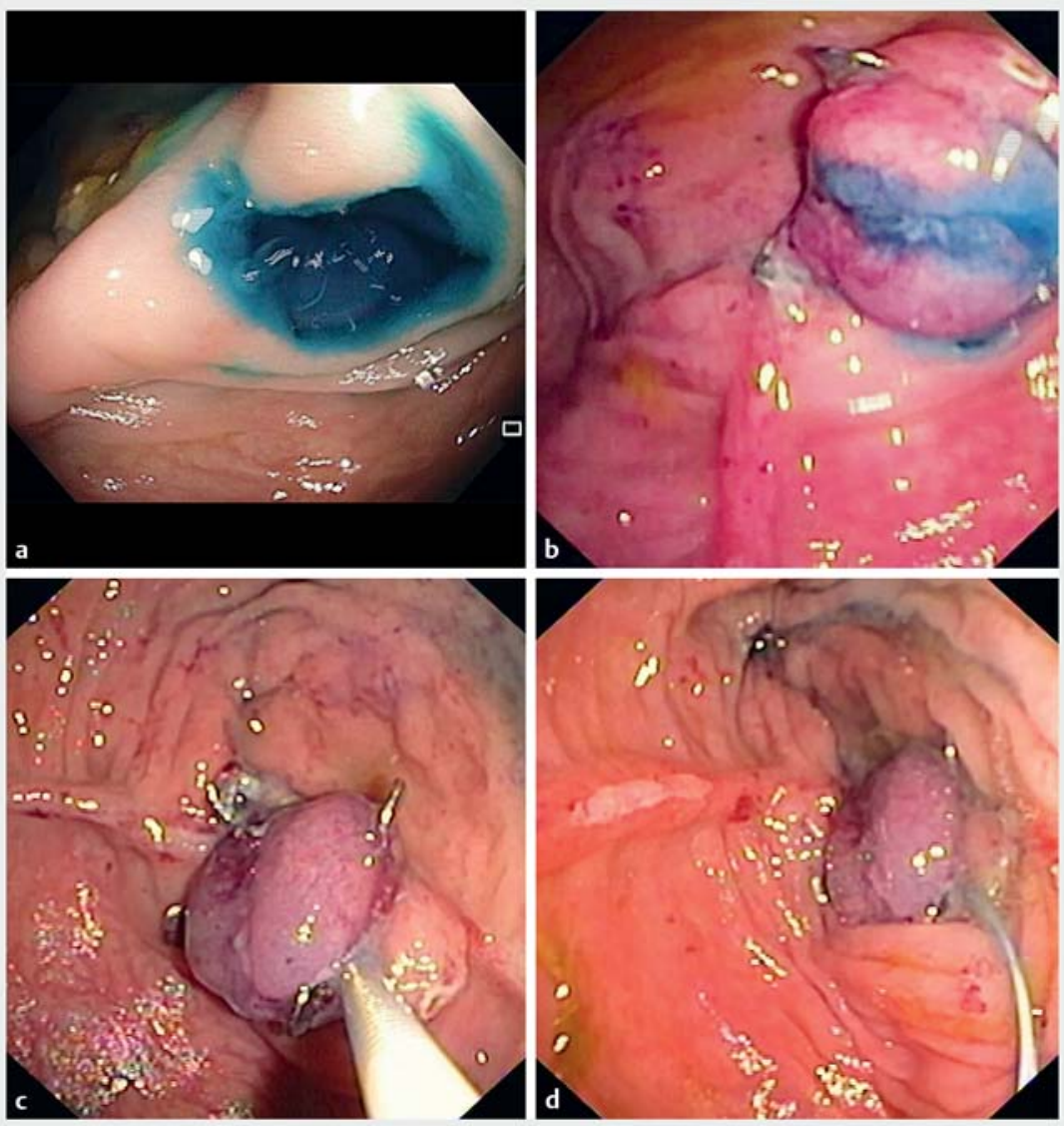

- Fig. 1 Endoscopic images. a Intraluminal methylene blue after instillation through the percutaneous drain. $\mathbf{b}$ Methylene blue still visible after correct placement of an over-thescope clip (OTSC). $\mathbf{c}$ Placement of a detachable snare beneath the jaws of the OTSC. $\mathbf{d}$ The OTSC and detachable snare in place, with methylene blue no longer visible.

at the ileal edge of the anastomosis ( $\vee$ Fig.1a). After the edges had been marked with argon plasma coagulation, a $14 / 6 \mathrm{~mm}$ over-the scope clip (OTSC; Ovesco Endoscopy AG, Tübingen, Germany) was placed. Despite correct placement, methylene blue leakage still occurred ( $\triangleright$ Fig.1b). A detachable snare was then placed beneath the jaws of the OTSC with the help of a foreign body retrieval forceps advanced through the second working channel ( $\mathbf{F i g . 1}$ c). Successful closure was achieved, with no intraluminal methylene blue visible following placement of the detachable snare ( Fig. $1 \mathrm{~d}$ ).

The percutaneous drain was removed 3 days later, and the patient was then discharged 2 days later. Colonoscopy was repeated 3 months later and showed a regular anastomosis and no evidence of the previously placed OTSC or detachable snare ( $\mathbf{F i g . 2}$ ). No contrast extravasation could be seen. The patient remains well.

ECFs are associated with significant morbidity and mortality [1]. Surgical intervention is typically difficult and is associated with significant complication rates. Although use of the OTSC may impact ECF treatment, a recent retrospec-

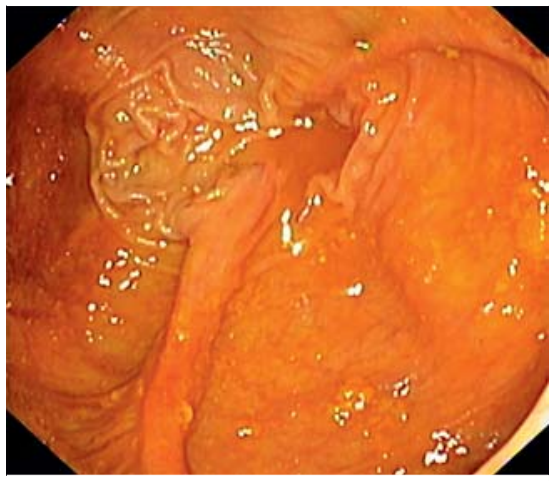

- Fig. 2 Endoscopic image 3 months later showing a regular anastomosis, without identification of the previously placed over-the-scope clip or detachable snare. 


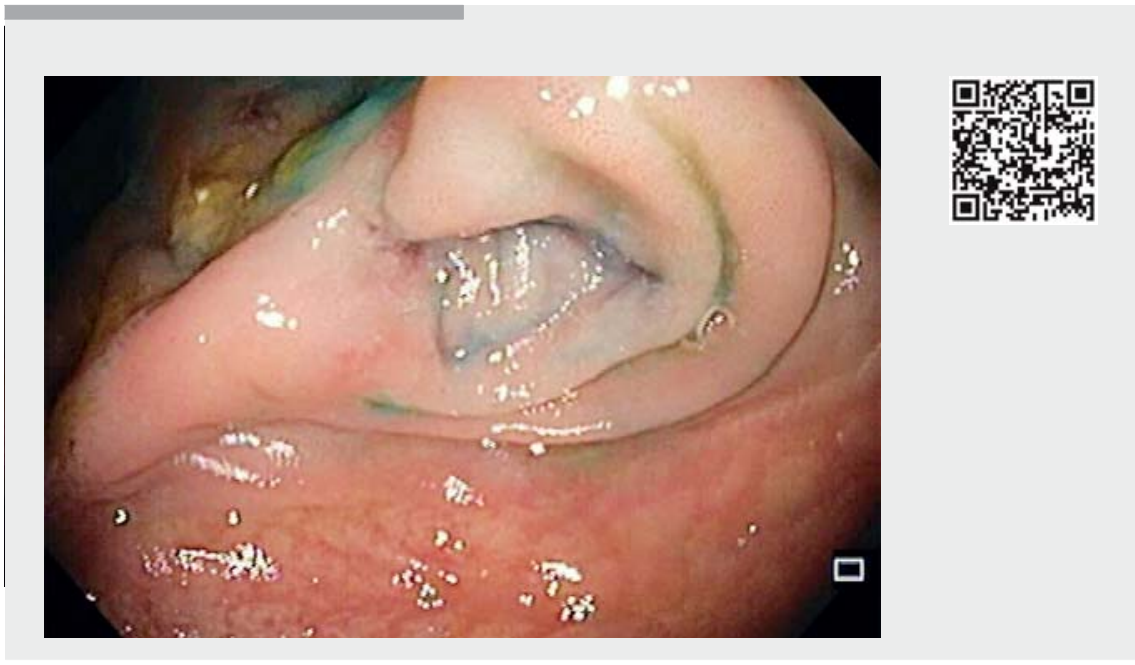

Video 1 Combined over-the-scope clip and detachable snare placement for closure of an enterocutaneous fistula.

tive review [2] reported only a $33 \%$ success rate for chronic fistulas (>30 days). Placement of the detachable snare below the OTSC may allow incorporation of a greater thickness of bowel wall, thus increasing the success rate.

Endoscopy_UCTN_Code_TTT_1AQ_2AG

Competing interests

None
The authors

\section{Eduardo Rodrigues-Pinto, Rui Morais,}

\section{Guilherme Macedo}

Gastroenterology Department, Centro

Hospitalar São João, Porto, Portugal

\section{Corresponding author}

\section{Eduardo Rodrigues-Pinto, MD}

Gastroenterology Department, Centro Hospitalar São João, Prof. Hernâni Monteiro 4200, 319 Porto, Portugal

Fax: +351-22-5513601

edu.gil.pinto@gmail.com

\section{References}

[1] Gribovskaja-Rupp I, Melton GB. Enterocutaneous fistula: proven strategies and updates. Clin Colon Rectal Surg 2016; 29: $130-137$

[2] Roy J, Sims K, Rider P et al. Endoscopic technique for closure of enterocutaneous fistulas. Surg Endosc 2019. doi:10.1007/s00464018-06646-1

\section{Bibliography}

DOI https://doi.org/10.1055/a-0889-7355

Published online: 9.5.2019

Endoscopy 2019; 51: E247-E248

(c) Georg Thieme Verlag KG

Stuttgart · New York

ISSN 0013-726X

\section{ENDOSCOPY E-VIDEOS}

https://eref.thieme.de/e-videos

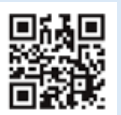

Endoscopy E-Videos is a free access online section, reporting on interesting cases and new techniques in gastroenterological endoscopy. All papers include a high quality video and all contributions are freely accessible online.

This section has its own submission website at

https://mc.manuscriptcentral.com/e-videos 